\title{
Constituents of Crinoidea, 4 . Isolation and Structure of Ceramides and Glucocerebrosides from the Feather Star Comanthus japonica
}

\author{
Masanori Inagaki, Akemi Oyama, Kazuyoshi AraO, and Ryuichi Higuchi* \\ Faculty of Pharmaceutical Sciences, Kyushu University; 3-1-1 Maidashi, Higashi-ku, Fukuoka 812-8582, Japan. \\ Received June 24, 2004; accepted August 2, 2004
}

\begin{abstract}
Five ceramides, JC-1—JC-5, and four glucocerebrosides, JCer-1-JCer-4, have been isolated from their parent ceramide and glucocerebroside molecular species JC and JCer obtained from the less polar lipid fraction of the chloroform/methanol extract of the feather star Comanthus japonica. The structures of these sphingolipids have been determined on the basis of chemical and spectroscopic evidence. Reversed-phase HPLC was effective at isolating these sphingolipids, revealing very close resemblance in their structures. JC-1, JC-3, JC-4, JC-5 and JCer-2, JCer-4 are newly found ceramides and glucocerebrosides, respectively.
\end{abstract}

Key words ceramide; glucocerebroside; feather star; Comanthus japonica

In our continuing research on biologically active sphingolipids from echinoderms, a series of studies on the isolation and structure elucidation of biologically active glycosphingolipids have been performed in our laboratory. ${ }^{1-6)}$ In a study of the sphingolipids of the feather star Comanthus japonica (Nipponumishida in Japanese), we reported the isolation and structure of inositolphosphoceramide ${ }^{7}$ and glycosyl inositolphosphoceramide-type gangliosides ${ }^{8)}$ from the polar lipid fraction of the chloroform/methanol extract of C. japonica. Continuing the preceding studies, the isolation and characterization of sphingolipids from the less polar lipid fraction was conducted. In this paper, we report the isolation and characterization of ceramides and glucocerebrosides from the whole bodies of $C$. japonica.

The less polar lipid fraction, which was obtained from the chloroform/methanol extract of the whole bodies of $C$. japonica, was subjected to repeated column chromatography to give a ceramide and a cerebroside molecular species, designated as JC and JCer, each showing a single spot on silica gel thin-layer chromatography (TLC).

JC exhibited strong hydroxy and amide absorptions in its IR spectrum and a series of quasi-molecular ion peaks due to $[\mathrm{M}-\mathrm{H}]^{-}$in its negative ion FAB mass spectrum. In its ${ }^{13} \mathrm{C}-$ NMR spectra (Fig. 1, Table 1), JC revealed the characteristic signals of a sphingosine-type ceramide possessing a non-hydroxylated fatty acid. Therefore, JC is suggested to be the molecular species of the typical type of ceramide. The structure of JC shown in Fig. 1 was characterized by comparison of its ${ }^{13} \mathrm{C}$-NMR spectral data with that of known cerami$\mathrm{des}^{9,10)}$ hitherto reported, and by means of the results of methanolysis followed by GC-MS analysis of the methanolysis products, fatty acid methyl ester (FAM) and long-chain base (LCB), as shown in Fig. 1 and the Experimental section.

Based on the considerable interest and importance in determining the molecular species composition of sphingolipids, isolation and structure elucidation of ceramide components in the molecular species JC was conducted. JC could be separated by reversed-phase HPLC into ten peaks, and could be recovered to give ten fractions, $1-10$. They behaved as pure compounds in HPLC, however, fractions 1, 2, 3, 6, 7 and 8 were regarded as still heterogeneous compounds, respectively, since they afforded plural molecular ion peaks in their negative ion FAB mass specra. Fractions 6 and
8 , the major fractions in the heterogeneous fractions, were successively separated by reversed-phase HPLC using another condition into two peaks, respectively, and could be recovered to three fractions, $6 \mathrm{a}, 8 \mathrm{a}$ and $8 \mathrm{~b}$, each showing a single molecular ion peak. When the seven fractions, 4, 5, 6a, $8 \mathrm{a}, 8 \mathrm{~b}, 9$ and 10 , believed to be pure substances, were methanolyzed and the FAM obtained from each fraction were analyzed by GC-MS, a single FAM was detected from five fractions $(4,5,8 b, 9,10)$ and two kinds of FAM were obtained from the other two fractions. Thus, five homogeneous components, designated as JC- $1-\mathrm{JC}-5$, could be obtained from the parent ceramide mixture, JC.

In the negative $\mathrm{FAB}$ mass spectrum, single quasi-molecular ion peaks $[\mathrm{M}-\mathrm{H}]^{-}$were observed at $\mathrm{m} / \mathrm{z}$ : $562(\mathrm{JC}-1$, JC-2), 592 (JC-3), 606 (JC-4), 620 (JC-5). They were confirmed as being the ceramide component of JC since their ${ }^{13} \mathrm{C}$-NMR spectra are identical to that of JC in the core moiety (Table 1).

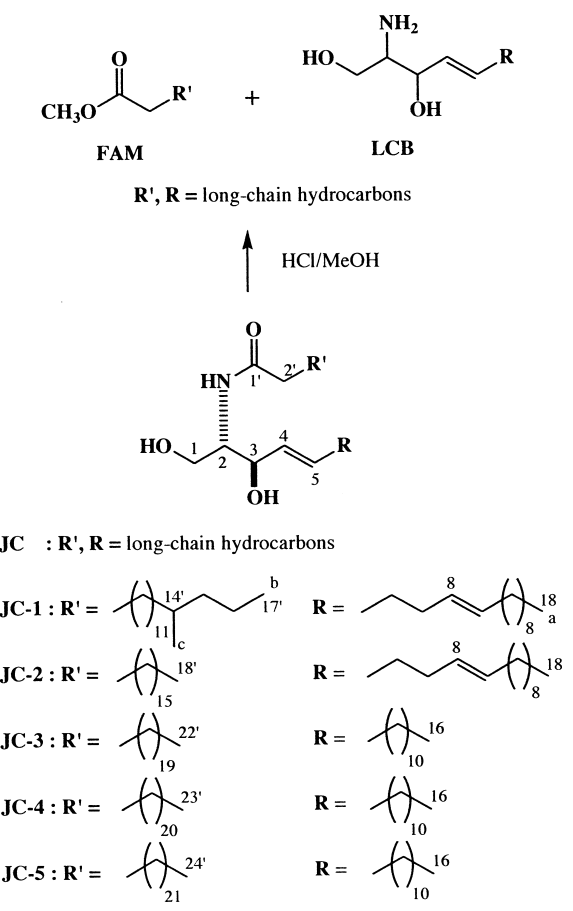

Fig. 1. Structures of JC-1-JC-5 
Table $1 .{ }^{13} \mathrm{C}$-NMR Spectral Data ( $\delta$ Values) of Ceramides in $\mathrm{CDCl}_{3}$

\begin{tabular}{|c|c|c|c|c|c|c|c|}
\hline $\mathrm{C}$ & & $\mathrm{JC}$ & JC-1 & JC-2 & $\mathrm{JC}-3$ & JC-4 & JC-5 \\
\hline 1 & $(t)$ & 62.5 & 62.5 & 62.5 & 62.6 & 62.6 & 62.6 \\
\hline 2 & (d) & 54.6 & 54.5 & 54.5 & 54.5 & 54.5 & 54.6 \\
\hline 3 & (d) & 74.6 & 74.7 & 74.7 & 74.7 & 74.8 & 74.8 \\
\hline 4 & (d) & 129.2 & $129.0^{d)}$ & $129.0^{e)}$ & 128.9 & 128.9 & 128.9 \\
\hline 5 & (d) & 134.2 & 133.6 & 133.6 & 134.3 & 134.3 & 134.3 \\
\hline $1^{\prime}$ & (s) & 173.9 & 173.9 & 173.9 & 173.9 & 173.8 & 173.8 \\
\hline $2^{\prime}$ & $(t)$ & 36.8 & 36.8 & 36.9 & 36.9 & 36.9 & 36.9 \\
\hline$=\mathrm{CH}$ & (d) & & 131.4 & 131.4 & & & \\
\hline$=\mathrm{CH}$ & (d) & & $129.2^{d)}$ & $129.2^{e)}$ & & & \\
\hline$=\mathrm{CHCH}_{2}$ & $(t)$ & & $32.3^{f)}$ & $32.6^{f)}$ & & & \\
\hline $\mathrm{CH}_{3}{ }^{a)}$ & $(q)$ & 14.1 & 14.0 & $14.1^{f)}$ & $14.1^{f f}$ & $14.1^{f f}$ & $14.1^{f f}$ \\
\hline $\mathrm{CH}_{3}{ }^{b)}$ & (q) & & 14.4 & & & & \\
\hline $\mathrm{CH}_{3}{ }^{c)}$ & (q) & & 19.7 & & & & \\
\hline
\end{tabular}

$a-c$ ) Terminal methyl groups in the normal and 1-methylbutyl type of side chain (see Fig. 1). $d$,e) Assignments may be interchanged in each vertical column. f) $2 \mathrm{C}$

Upon methanolysis, they yielded methyl octadecanoate (JC-1, JC-2), methyl docosanoate (JC-3), methyl tricosanoate (JC-4), methyl tetracosanoate (JC-5), and therefore their LCB moieties are regarded as being 2-amino-1,3-dihydroxyoctadecadiene (JC-1, JC-2), 2-amino-1,3-dihydroxy-4-hexadecene (JC-3, JC-4, JC-5) by determining their molecular masses and fatty acid components. This evidence is supported by the fact that these LCB have been detected in the LCB mixture obtained from the parent ceramide, JC.

In the ${ }^{13} \mathrm{C}-\mathrm{NMR}$ spectrum of $\mathrm{JC}-1$, signals due to two methyl groups were observed at $\delta: 14.4$ and 19.7 in addition to that of a terminal one at $\delta: 14.0$ due to a normal type of side chain, which suggests the existence of a branched side chain residue in the fatty acyl or long-chain base moiety. The structure of the side chain moiety is suggested to be a 1-methylbutyl group by the fact that the ${ }^{13} \mathrm{C}$-NMR chemical shift values due to the branched side chain moiety of JC-1 are in good agreement with those of a known cerebroside ${ }^{11)}$ possessing a 1-methylbutyl moiety as shown in Fig. 2. Furthermore, the existence of the branched side chain moiety in the fatty acyl part was verified by the fact that FAM (C18) from $\mathrm{JC}-1$ revealed a different retention time from methyl stearate (C18) in GC-MS analysis using different conditions from those hitherto mentioned (see Experimental).

The location and geometry of the double bond in the LCB moiety of JC-1 and JC-2 were determined as follows.

The mass spectra of the dimethyl disulfide (DMDS) derivatives $^{12,13)}$ of JC-1 and JC-2 show remarkable fragment-ion peaks at $m / z$ : 187 due to cleavage of the bond between the carbons bearing the methylthio groups (Fig. 3). These data indicate that the double bond in the LCB moieties of JC-1 and JC-2 are both located at C- 8 . Furthermore, the geometry $(E)$ of the double bonds of both compounds were determined from the $\delta$ values (32.3 in JC-1, 32.6 in JC-2) of the allylic carbon atoms obtained from their ${ }^{1} \mathrm{H}$-detected heteronuclear multiple-bond connectivity (HMBC) spectra, since allylic carbon signals of $Z$ - and $E$-isomers are observed at $\delta \mathrm{ca}$. $26-27$ and $\delta$ ca. $31-32$, respectively. ${ }^{14)}$

On the basis of the above data, the relative structures of JC-1-JC-5 are proposed to be the sphingosine-type ceramides as shown in Fig. 1. Furthermore, the optical rotations of JC-2, JC-3, JC-4, and JC-5 ( -8.8 to -2.4$)$ and the synthetic $(2 S, 3 R, 4 E)$-2-(hecadecanoylamino)-1,3-dihydroxy4-octadecene $(-4.6)^{9)}$ suggested that JC-2 - JC-5 have the

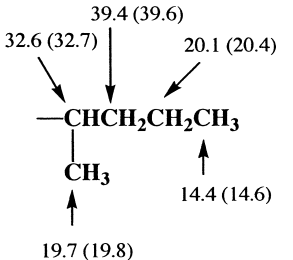

Fig. 2. ${ }^{13} \mathrm{C}$-NMR Chemical Shifts ( $\delta$ Values) of the Side Chain Moiety of the Fatty Acyl Part of JC-1

Reference values ${ }^{11)}$ are in parentheses.<smiles>C=CC(=O)NC(C)C(C)C(O)C(C)C(C)CCC(C)(C)C(C)(C)C</smiles>

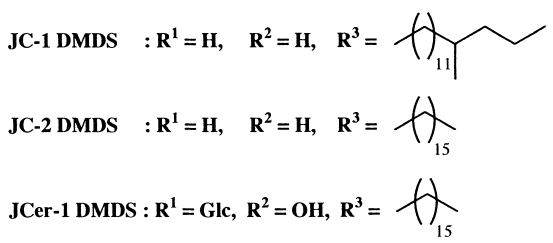

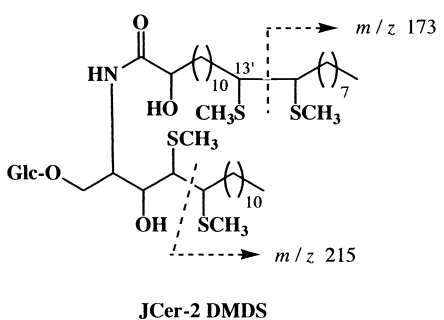

Fig. 3. Mass Fragmentation of DMDS Derivatives of JC-1, JC-2, JCer-1 and JCer-2

same absolute configuration, D-erythro $(2 S, 3 R)$, as that of the synthetic one. The absolute stereochemistry of JC-1 including that of C-14' is still unknown because of a lack of a sample. Therefore, the structures of these ceramides are regarded as $\left(2 S^{*}, 3 R^{*}, 4 E, 8 E\right)-2$-(14-methylheptadecanoylamino)-1,3dihydroxy-4,8-octadecadiene (JC-1), (2S,3R,4E,8E)-2-(octa- 
Table 2. ${ }^{13} \mathrm{C}-\mathrm{NMR}$ Spectral Data ( $\delta$ Values) of Glucocerebrosides in $\mathrm{C}_{5} \mathrm{D}_{5} \mathrm{~N}$

\begin{tabular}{|c|c|c|c|c|c|c|}
\hline $\mathrm{C}$ & & JCer & JCer-1 & JCer-2 & JCer-3 & JCer-4 \\
\hline 1 & $(\mathrm{t})$ & 70.1 & 70.1 & 70.1 & 70.1 & 70.7 \\
\hline 2 & (d) & 54.6 & 54.7 & 54.7 & 54.7 & 52.3 \\
\hline 3 & (d) & $72.3^{a)}$ & $72.4^{b)}$ & $72.4^{c)}$ & $72.4^{(d)}$ & 76.0 \\
\hline 4 & (d) & 131.7 & 131.1 & 131.7 & 131.7 & 72.8 \\
\hline 5 & (d) & 132.8 & 132.1 & 132.8 & 132.8 & \\
\hline $1^{\prime}$ & $(\mathrm{s})$ & 175.6 & 175.6 & 175.7 & 175.6 & 173.6 \\
\hline $2^{\prime}$ & (d) & $72.5^{a)}$ & $72.6^{b)}$ & $72.6^{c)}$ & $72.6^{d)}$ & $36.9^{g)}$ \\
\hline$=\mathrm{CH}$ & (d) & & $129.9^{f)}$ & $130.2^{f)}$ & & \\
\hline$=\mathrm{CHCH}_{2}$ & $(\mathrm{t})$ & & $32.9^{f)}$ & $27.5^{f)}$ & & \\
\hline $\mathrm{CH}_{3}$ & (q) & 14.2 & $14.2^{f)}$ & $14.2^{f)}$ & $14.2^{f)}$ & $14.2^{f)}$ \\
\hline $1^{\prime \prime}$ & (d) & 105.6 & 105.6 & 105.5 & 105.6 & 105.7 \\
\hline $2^{\prime \prime}$ & (d) & 75.1 & 75.1 & 75.1 & 75.1 & 75.2 \\
\hline $3^{\prime \prime}$ & (d) & 78.4 & 78.5 & 78.4 & 78.5 & $78.5^{e)}$ \\
\hline $4^{\prime \prime}$ & (d) & 71.5 & 71.6 & 71.6 & 71.6 & 71.7 \\
\hline $5^{\prime \prime}$ & (d) & 78.4 & 78.5 & 78.4 & 78.5 & $78.6^{e)}$ \\
\hline $6^{\prime \prime}$ & $(t)$ & 62.6 & 62.7 & 62.7 & 62.7 & 62.8 \\
\hline
\end{tabular}

$a-e$ ) Assignments may be interchanged in each vertical column. f) $2 \mathrm{C} . \quad g$ ) triplet (t).

decanoylamino)-1,3-dihydroxy-4,8-octadecadiene (JC-2), (2S,3R,4E)-2-(docosanoylamino)-1,3-dihydroxy-4-hexadecene (JC-3), (2S,3R,4E)-2-(tricosanoylamino)-1,3-dihydroxy-4-hexadecene (JC-4), (2S,3R,4E)-2-(tetracosanoylamino)-1,3-dihydroxy-4-hexadecene (JC-5).

In its IR spectrum, JCer exhibit strong hydroxy and amide absorptions. JCer reveal the characteristic signals of a sphingosine-type $\beta$-glucocerebroside possessing a 2-hydroxy fatty acid in its ${ }^{13} \mathrm{C}$-NMR spectrum (Fig. 4, Table 2). HPLC analysis of JCer suggested JCer was the molecular species of cerebroside since JCer showed eleven peaks in its reversed-phase HPLC.

Based on the idea mentioned above, preparative separation of the components in the molecular species JCer was conducted and eleven fractions, 1 to 11 could be recovered. They behaved as pure compounds in the reversed-phase HPLC, however, fractions other than 2, 5, 10 and 11 were regarded as still heterogeneous compounds since they afforded diverse quasi-molecular ion peaks $[\mathrm{M}+\mathrm{Na}]^{+}$in their positive ion FAB mass spectra. Fractions 2, 5, 10 and 11 were successively methanolyzed with methanolic hydrochloric acid to yield a single FAM. Thus, four components, designated as JCer-1, JCer-2, JCer-4 and JCer-3, could be obtained in a pure state from the parent glucocerebroside mixture.

JCer-1, JCer-2 and JCer-3 revealed quasi-molecular ion peaks $[\mathrm{M}+\mathrm{Na}]^{+}$at $m / z: 764$ (JCer-1), 792 (JCer-2), 822 (JCer-3), respectively, in their positive ion FAB mass spectra. They must be the glucocerebroside components of JCer since their ${ }^{13} \mathrm{C}$-NMR spectra are identical to that of JCer, except for the signal due to an additional olefinic group in JCer-1 and JCer-2 (Table 2).

By taking the molecular masses of JCer-1 (741), JCer-2 (769), JCer-3 (799) and FAM of JCer-1 (methyl 2-hydroxyoctadecanoate), JCer-2 (methyl 2-hydroxydocosenoate), and JCer-3 (methyl 2-hydroxytetracosanoate) into account, their LCB components are regarded as 2-amino-1,3-dihydroxyoctadecadiene (JCer-1) and 2-amino-1,3-dihydroxy-4-hexadecene (JCer-2, JCer-3). The location and geometry of the double bonds in the LCB and fatty acyl moiety of JCer-1 and JCer-2 were determined in the same way as in the ceramides, JC-1 and JC-2. Namely, the mass spectra of the DMDS derivatives of JCer-1 and JCer- 2 show remarkable fragment-

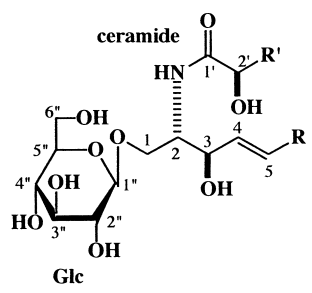

JCer : R', $\mathbf{R}=$ long-chain hydrocarbons
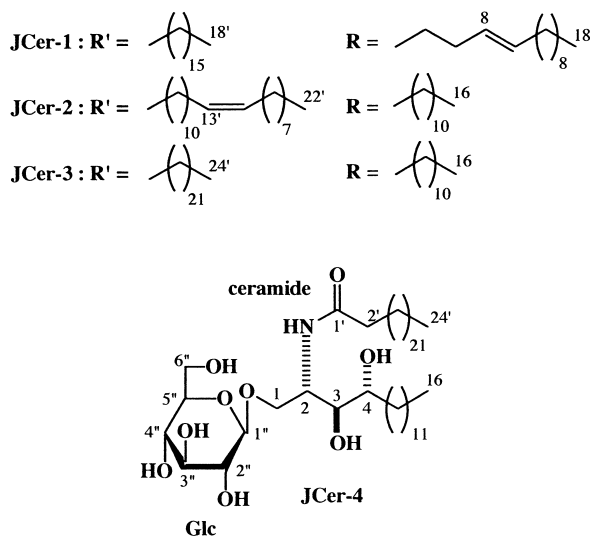

Fig. 4. Structures of JCer-1-JCer-4

ion peaks at $m / z$ : 187 and 173 , respectively, indicating that the double bonds in the LCB and fatty acyl moieties of JCer1 and JCer- 2 are located at $\mathrm{C}-8$ and $\mathrm{C}-13^{\prime}$, respectively, as shown in Figs. 3 and 4 . The geometry of the double bonds was characterized as $E(\mathrm{C}-8)$ and $Z\left(\mathrm{C}-13^{\prime}\right)$ from the $\delta$ value (32.9 in JCer-1, 27.5 in JCer-2) of the allylic carbon atoms.

On the basis of the above evidence, the relative structures of JCer-1-JCer-3 are proposed to be the $\beta$-glucopyranosyl ceramides as shown in Fig. 4. When the optical rotations of JCer-1, JCer-2 and JCer-3 $(+7.8,+9.7,+5.6)$ were compared with that of the asteriacerebroside A, 1- $O$ - $(\beta$-D-glucopyranosyl)-(2S,3R,4E,13Z)-2-[(2R)-2-hydroxypentadecanoylamino]-1,3-dihydroxy-4,13-docosadiene, $(+8.5),{ }^{11)}$ they were found to have the same absolute configuration as that of the known one. Accordingly, the structures of these glucocerebrosides are regarded as 1-O- $(\beta$-D-glucopyranosyl $)$ $(2 S, 3 R, 4 E, 8 E)-2-[(2 R)$-2-hydroxyoctadecanoylamino]-1,3-di- 
hydroxy-4,8-octadecadiene (JCer-1), 1- $O$-( $\beta$-D-glucopyranosyl)-( $2 S, 3 R, 4 E)-2-[(2 R, 13 Z)-2$-hydroxy-13-docosenoylamino]-1,3-dihydroxy-4-hexadecene (JCer-2), 1- $O$ - $(\beta$-D-glucopyranosyl)-( $2 S, 3 R, 4 E)-2-[(2 R)-2$-hydroxytetracosanoylamino]-1,3-dihydroxy-4-hexadecene (JCer-3).

On the other hand, JCer-4 revealed characteristic signals of a phytosphingosine-type $\beta$-glucocerebroside possessing an unsubstituted fatty acid in its ${ }^{13} \mathrm{C}$-NMR spectrum (Table 2), although JCer-4 obtained from its parent sphingosine-type glucocerebroside molecular species JCer. JCer-4 shows a quasi-molecular ion peak $[\mathrm{M}+\mathrm{Na}]^{+}$at $m / z: 824$ in its positive ion FAB mass spectrum and afforded methyl tetracosanoate upon methanolysis, indicating its LCB component is 2-amino-1,3,4-trihydroxy-hexadecane. Therefore, if the glucose and LCB of JCer-4 are assumed to be most commonly found in D and D-ribo $(2 S, 3 S, 4 R)$ series, JCer-4 is characterized as $1-O$-( $\beta$-D-glucopyranosyl)-( $2 S, 3 S, 4 R)-2$ (tetracosanoylamino)-1,3,4-trihydroxy-hexadecane, as shown in Fig. 4. Since JCer-4 is a minor component of JCer, the signals due to JCer-4 must be submerged under other signals in the ${ }^{13} \mathrm{C}$-NMR spectrum of JCer.

Of the five ceramides and four glucocerebrosides thus obtained in a pure state and characterized, JCer-1 was found to be identical with a glucocerebroside isolated from Arisaema amurense, which has been reported to display significant antihepatotoxic activity. ${ }^{15)}$ Although JC-2 and JCer-3 are known to be components of molecular species of a ceramide and glucocerebroside obtained from the soft coral Lobophytum species ${ }^{16)}$ and sea cucumber Holothuria coronopertus $a,{ }^{17)}$ respectively, we believe the present study is the first regarding the isolation of these sphingolipids.

JC-1, JC-3, JC-4, JC-5, JCer-2 and JCer-4 are, to the best of our knowledge, new ceramides and glucocerebrosides. Moreover, the fatty acyl moiety of JC-1 is unique in that it includes a 1-methylbutyl moiety, while the fatty acyl moiety of every sphingolipid of echinoderms belongs to the normal form. JCer-4 is also unique in that it is the first type of cerebroside from echinoderms composed of a phytosphingosine base and non-hydroxylated fatty acyl moiety. For studies of the cerebrosides so far obtained from the starfish and the sea cucumber in our laboratory, the reader is referred to our previous papers. ${ }^{11,18-24)}$

\section{Experimental}

Melting points were determined on a micro melting point apparatus (Yanako MP-3) without correction. Optical rotations were measured with a Jasco Dip-307 digital polarimeter at $25^{\circ} \mathrm{C}$. IR spectra were obtained on a Jasco FT/IR-410 infrared spectrophotometer. ${ }^{1} \mathrm{H}$ - and ${ }^{13} \mathrm{C}-\mathrm{NMR}$ spectra were recorded on a Jeol GX-270 spectrometer $(270,67.8 \mathrm{MHz})$ or a Varian Unity500 spectrometer $(500,125 \mathrm{MHz})$. FAB-MS spectra were acquired with a Jeol SX102A mass spectrometer [xenon atom beam; matrix, $m$-nitrobenzyl alcohol (positive ion), triethyleneglycol (negative ion)]. GC-MS were taken with a Shimadzu QP-1000 [EI mode; ionizing potential, $70 \mathrm{eV}$; separator and ion-source temperature $250^{\circ} \mathrm{C}$; column (A), TC-1701 $(0.53 \mathrm{~mm} \times 12 \mathrm{~m}$, GL Science Inc.); column (B), $2 \%$ OV-17 $(2.6 \mathrm{~mm} \times 1.1 \mathrm{~m}$, Shimadzu); carrier gas, He]. HPLC was performed with PU-980 and RI-930 (Jasco) as a pump and an RI detector, respectively.

Separation of $\mathbf{J C}$ and JCer Refer to our previous paper ${ }^{7)}$ for the extraction and fractionation of the less polar lipid fraction from the whole bodies of the feather star Comanthus japonica $(7.6 \mathrm{~kg})$. The less polar lipid fraction, namely $\mathrm{AcOEt} / n-\mathrm{BuOH}$ soluble fraction $(164.6 \mathrm{~g})$, was partitioned between $n$-hexane and $\mathrm{MeOH}$ to give a $\mathrm{MeOH}$ soluble fraction $(74.6 \mathrm{~g})$. The $\mathrm{MeOH}$ soluble portion (37.5 g) was chromatographed on silica gel (solvent $\mathrm{CHCl}_{3} / \mathrm{MeOH}, 98: 2$ to $9: 1$ ) to give five fractions. Successive column chromatography of fractions 2 and 3 (silica gel, solvent $\mathrm{CHCl}_{3} / \mathrm{MeOH}$,
99: 1$)$ afforded JC ( $43 \mathrm{mg})(R f=0.68)$ [silica gel TLC, solvent $\mathrm{CHCl}_{3} / \mathrm{MeOH}$ $(9: 1)]$. Fraction 4 was further chromatographed on Sephadex LH-20 (sovent $\left.\mathrm{CHCl}_{3} / \mathrm{MeOH}, 1: 1\right)$ to afford JCer $(32 \mathrm{mg})(R f=0.25)$ [silica gel TLC, solvent $\left.\mathrm{CHCl}_{3} / \mathrm{MeOH} / \mathrm{H}_{2} \mathrm{O}(9: 1.5: 0.05)\right]$.

JC: Amorphous powder. IR (KBr) cm ${ }^{-1}: 3340(\mathrm{OH}), 1620,1540$ (amide). Negative-ion FAB-MS $m / z: 530-640[\mathrm{M}-\mathrm{H}]^{-}$series. ${ }^{13} \mathrm{C}-\mathrm{NMR}$ : see Table 1.

JCer: Amorphous powder. IR $(\mathrm{KBr}) \mathrm{cm}^{-1}: 3365(\mathrm{OH}), 1644,1536$ (amide). Positive-ion FAB-MS $m / z: 730-840[\mathrm{M}+\mathrm{Na}]^{+}$series. ${ }^{13} \mathrm{C}-\mathrm{NMR}$ : see Table 2.

Methanolysis of $\mathbf{~ J C} \mathrm{JC}(1 \mathrm{mg})$ was heated with $5 \% \mathrm{HCl}$ in $\mathrm{MeOH}$ $(1 \mathrm{ml})$ at $70^{\circ} \mathrm{C}$ for $2 \mathrm{~h}$. The reaction mixture was then extracted with $n$-hexane, and the extract was concentrated in vacuo to yield a mixture of FAM. The MeOH layer was concentrated in vacuo to give a mixture of LCB.

GC-MS Analysis of FAM from JC A FAM mixture from JC was subjected to GC-MS [column (A), column temp. $150-260^{\circ} \mathrm{C}$ (rate of temp. increase $\left.\left.8^{\circ} \mathrm{C} / \mathrm{min}\right)\right]$. The results were as follows: methyl octadecanoate, $t_{\mathrm{R}}[\mathrm{min}]=5.9, \mathrm{~m} / \mathrm{z}: 298\left(\mathrm{M}^{+}\right), 255(\mathrm{M}-43)^{+}$; methyl docosanoate, $t_{\mathrm{R}}=9.7$, $m / z: 354\left(\mathrm{M}^{+}\right), 311(\mathrm{M}-43)^{+}$; methyl tricosanoate, $t_{\mathrm{R}}=10.6, m / z: 368\left(\mathrm{M}^{+}\right)$, $325(\mathrm{M}-43)^{+}$; methyl tetracosanoate, $t_{\mathrm{R}}=11.5, \mathrm{~m} / \mathrm{z}: 382\left(\mathrm{M}^{+}\right), 339$ $(\mathrm{M}-43)^{+}$

GC-MS Analysis of TMS Ethers of LCB from JC The mixture of LCB from JC was heated with 1-(trimethylsilyl) imidazole-pyridine $(1: 1)$ for $20 \mathrm{~min}$ at $70^{\circ} \mathrm{C}$ and the reaction mixture (TMS ethers) was analyzed by GC-MS [column (A), column temp. $180-250^{\circ} \mathrm{C}$ (rate of temp. increase $\left.4^{\circ} \mathrm{C} / \mathrm{min}\right)$ ]. The results were as follows: 2-amino-1,3-dihydroxy-4-hexadecene, $t_{\mathrm{R}}[\mathrm{min}]=5.5, \mathrm{~m} / \mathrm{z}: 312(\mathrm{M}-103)^{+}, 283(\mathrm{M}-132)^{+}, 132 ; 2$-amino1,3-dihydroxyoctadecadiene, $t_{\mathrm{R}}=8.1, \mathrm{~m} / z: 338(\mathrm{M}-103)^{+}, 309(\mathrm{M}-132)^{+}$, 132.

Isolation of Ceramide Components JC-1-JC-5 from JC HPLC of JC [condition: column, Wakosil 5C18 $(10 \times 250 \mathrm{~mm})$; solvent, $100 \% \mathrm{MeOH}$; flow rate, $3.0 \mathrm{ml} / \mathrm{min}$; detector, RI] showed ten peaks. Using this condition, $40 \mathrm{mg}$ of JC was separated by HPLC to give ten fractions, fr. $1, t_{\mathrm{R}}$ [min] (yield) $=23.6(0.8 \mathrm{mg})$, fr. 2, $25.6(0.1 \mathrm{mg})$, fr. 3, $27.2(1.4 \mathrm{mg})$, fr. $4,29.0$ $(1.2 \mathrm{mg})$, fr. $5,31.6(2.4 \mathrm{mg})$, fr. $6,37.2(3.4 \mathrm{mg})$, fr. $7,43.8(1.1 \mathrm{mg})$, fr. 8 , $50.2(9.0 \mathrm{mg})$, fr. $9,61.0(2.3 \mathrm{mg})$, fr. $10,70.6(8.9 \mathrm{mg})$.

Fractions 6 and 8 successively separated, respectively, by HPLC [condition: column, Cosmosil 5C18-AR-II $(4.6 \times 250 \mathrm{~mm})$; solvent, $100 \% \mathrm{MeOH}$ (fr. 6), $98 \% \mathrm{MeOH}$ (fr. 8); flow rate, $0.5 \mathrm{ml} / \mathrm{min}$; detector, $\mathrm{RI}$ ] to yield two compounds each fr. $6 \mathrm{a}, t_{\mathrm{R}}[\mathrm{min}]$ (yield) $=28.2(1.3 \mathrm{mg})$, fr. $6 \mathrm{~b}, 31.2$ (trace), fr. $8 \mathrm{a}, 66.2(1.7 \mathrm{mg})$, fr. $8 \mathrm{~b}, 70.4(3.5 \mathrm{mg})$.

JC-1 (fr. 4): Amorphous powder, mp $68-70^{\circ} \mathrm{C}$. Negative-ion FAB-MS $m / z: 562[\mathrm{M}-\mathrm{H}]]^{-} .{ }^{13} \mathrm{C}-\mathrm{NMR}$ : see Table 1.

JC-2 (fr. 5): Amorphous powder, mp $82-85^{\circ} \mathrm{C} .[\alpha]_{\mathrm{D}}-8.8^{\circ}(c=0.09$, $\mathrm{CHCl}_{3}$ ). Negative-ion FAB-MS m/z: $\left.562[\mathrm{M}-\mathrm{H}]\right]^{-} .{ }^{13} \mathrm{C}-\mathrm{NMR}$ : see Table 1.

JC-3 (fr. 8b): Amorphous powder, mp $77-79^{\circ} \mathrm{C} .[\alpha]_{\mathrm{D}}-2.4^{\circ}(c=0.25$, $\mathrm{CHCl}_{3}$ ). Negative-ion FAB-MS m/z: $592[\mathrm{M}-\mathrm{H}]^{-} .{ }^{13} \mathrm{C}-\mathrm{NMR}$ : see Table 1.

JC-4 (fr. 9): Amorphous powder, mp $76-78^{\circ} \mathrm{C} .[\alpha]_{\mathrm{D}}-4.6^{\circ}(c=0.15$, $\mathrm{CHCl}_{3}$ ). Negative-ion FAB-MS m/z: $606[\mathrm{M}-\mathrm{H}]^{-} .{ }^{13} \mathrm{C}-\mathrm{NMR}$ : see Table 1.

JC-5 (fr. 10): Amorphous powder, mp $85-87^{\circ} \mathrm{C} .[\alpha]_{\mathrm{D}}-4.3^{\circ}(c=0.58$, $\mathrm{CHCl}_{3}$ ). Negative-ion FAB-MS m/z: $620[\mathrm{M}-\mathrm{H}]^{-} .{ }^{13} \mathrm{C}-\mathrm{NMR}$ : see Table 1.

Methanolysis of JC-1-JC-5 In the same manner as described for JC, JC-1 - JC-5 were methanolyzed and the reaction mixtures were worked up to give the FAM of each compound. Each FAM was subjected to GC-MS under the same conditions as described for the FAMs from JC, and methyl octadecanoate (from JC-1, JC-2), methyl docosanoate (from JC-3), methyl tricosanoate (from JC-4), methyl tetracosanoate (from JC-5) were detected.

GC-MS Analysis of FAM from JC-1 Using Another Condition The above mentioned FAM (C18) from JC-1 was subjected to GC-MS [column (A), column temp. $130-200^{\circ} \mathrm{C}$ (rate of temp. increase $8^{\circ} \mathrm{C} / \mathrm{min}$ )]. The results were as follows: FAM from $\mathrm{JC}-1, t_{\mathrm{R}}[\mathrm{min}]=8.7$; methyl stearate, $t_{\mathrm{R}}=9.2$.

DMDS Derivatives of JC-1 and JC-2 $0.3 \mathrm{mg}$ each of JC- 1 and JC-2 was dissolved in carbon disulfide $(0.2 \mathrm{ml})$ and dimethyl disulfide (DMDS, $0.2 \mathrm{ml})$ and iodine $(1 \mathrm{mg})$ were added to the solution. The resulting mixture was kept at $60^{\circ} \mathrm{C}$ for $40 \mathrm{~h}$ in a small-volume sealed vial. The reaction was subsequently quenched with aqueous $\mathrm{Na}_{2} \mathrm{~S}_{2} \mathrm{O}_{3}(5 \%)$, and the mixture was extracted with $n$-hexane $(0.3 \mathrm{ml})$. The extract was concentrated and the residue (DMDS derivative) was analyzed by EIMS [Shimadzu QP-1000 (direct injection)]: DMDS derivative of JC-1, $\mathrm{m} / \mathrm{z}$ : 187; DMDS derivative of JC-2, $m / z: 187$ (see Fig. 3).

Isolation of Glucocerebroside Components JCer-1-JCer-4 from JCer HPLC of JCer [condition: column, Wakosil 5 C18 $(10 \times 250 \mathrm{~mm})$; solvent, $100 \% \mathrm{MeOH}$; flow rate, $2.5 \mathrm{ml} / \mathrm{min}$; detector, $\mathrm{RI}$ ] showed eleven 
peaks. Using this condition, $30 \mathrm{mg}$ of JCer was separated by HPLC to give eleven fractions, fr. $1, t_{\mathrm{R}}[\mathrm{min}]$ (yield) $=24.4(0.7 \mathrm{mg})$, fr. $2,25.8(0.4 \mathrm{mg})$, fr. 3, $27.8(0.7 \mathrm{mg})$, fr. $4,29.6(0.7 \mathrm{mg})$, fr. 5, $32.2(3.8 \mathrm{mg})$, fr. $6,37.4(1.0 \mathrm{mg})$, fr. $7,38.8(1.4 \mathrm{mg})$, fr. $8,43.2(3.8 \mathrm{mg})$, fr. $9,50.0(0.7 \mathrm{mg})$, fr. $10,52.2$ (1.5 mg), fr. 11, $58.4(2.2 \mathrm{mg})$.

JCer-1 (fr. 2): Amorphous powder, mp $83-85^{\circ} \mathrm{C} .[\alpha]_{\mathrm{D}}+7.8^{\circ}(c=0.43$, $n$-PrOH). Positive-ion FAB-MS $m / z: 764[\mathrm{M}+\mathrm{Na}]{ }^{+} .{ }^{13} \mathrm{C}$-NMR: see Table 2.

JCer-2 (fr. 5): Amorphous powder, mp $128-130^{\circ} \mathrm{C}$. $[\alpha]_{\mathrm{D}}+9.7^{\circ}$ $\left(c=0.17, n\right.$-PrOH). Positive-ion FAB-MS $m / z: 792[\mathrm{M}+\mathrm{Na}]^{+} .{ }^{13} \mathrm{C}-\mathrm{NMR}$ : see Table 2.

JCer-4 (fr. 10): Amorphous powder, mp $105-108^{\circ} \mathrm{C} .[\alpha]_{\mathrm{D}}+1.2^{\circ}$ $(c=0.12, n \text {-PrOH). Positive-ion FAB-MS } m / z: 824[\mathrm{M}+\mathrm{Na}]]^{+} .{ }^{13} \mathrm{C}-\mathrm{NMR}$ : see Table 2.

JCer-3 (fr. 11): Amorphous powder, mp $125-128^{\circ} \mathrm{C} .[\alpha]_{\mathrm{D}}+5.6^{\circ}$ $\left(c=0.17, n\right.$-PrOH). Positive-ion FAB-MS $m / z: 822[\mathrm{M}+\mathrm{Na}]{ }^{+} .{ }^{13} \mathrm{C}$-NMR: see Table 2 .

Methanolysis of JCer-1-JCer-4 One milligram each of JCer-1, JCer2, JCer-3 and JCer-4, respectively, was heated with $5 \% \mathrm{HCl}$ in $\mathrm{MeOH}(1 \mathrm{ml})$ at $80^{\circ} \mathrm{C}$ for $10 \mathrm{~h}$. The reaction mixture was then extracted with $n$-hexane, and the extract was concentrated in vacuo to yield the FAM of each compound.

GC-MS Analysis of FAM from JCer-1-JCer-4 The above mentioned FAMs were subjected to GC-MS [column (A) for FAM from JCer-1; column (B) for FAMs from JCer-2 - JCer-4, column temp. $150-260^{\circ} \mathrm{C}$ (rate of temp. increase $8{ }^{\circ} \mathrm{C} / \mathrm{min}$ )]. The results were as follows: FAM from JCer-1, methyl 2-hydroxyoctadecanoate, $t_{\mathrm{R}}[\mathrm{min}]=7.4, \mathrm{~m} / z: 314\left(\mathrm{M}^{+}\right), 255$ $(\mathrm{M}-59)^{+}$; FAM from JCer-2, methyl 2-hydroxydocosenoate, $t_{\mathrm{R}}=12.9, \mathrm{~m} / \mathrm{z}$ : $368\left(\mathrm{M}^{+}\right), 309(\mathrm{M}-59)^{+}$; FAM from JCer-3, methyl 2-hydroxytetracosanoate, $t_{\mathrm{R}}=15.0, \mathrm{~m} / z: 398\left(\mathrm{M}^{+}\right), 339(\mathrm{M}-59)^{+}$; FAM from JCer-4, methyl tetracosanoate, $t_{\mathrm{R}}=13.3, \mathrm{~m} / \mathrm{z}: 382\left(\mathrm{M}^{+}\right), 339(\mathrm{M}-43)^{+}$.

DMDS Derivatives of JCer-1 and JCer-2 Treated in the same manner as in JC-1 and JC-2, DMDS derivatives of JCer-1 and JCer-2 were obtained. They were analyzed by EIMS and positive-ion FABMS, respectively: DMDS derivative of JCer-1, $m / z$ : 187; DMDS derivative of JCer-2, $m / z: 173,215$ (see Fig. 3).

Acknowledgements We thank Mr. Y. Tanaka and Ms. Y. Soeda of the Faculty of Pharmaceutical Sciences, Kyushu University, for the NMR measurements. This work was supported in part by Grants-in-Aid for Scientific Research Nos. 13780468 and 13024260 (Priority Area A) from the Ministry of Education, Culture, Science, Sports and Technology, Japan, which are gratefully acknowledged.

\section{References}

1) Higuchi R., Inagaki K., Natori T., Komori T., Kawajiri S., Liebigs Ann. Chem., 1991, 1—10 (1991).
2) Higuchi R., Inukai K., Jhou J.-X., Honda M., Komori T., Tsuji S., Nagai Y., Liebigs Ann. Chem., 1993, 359-366 (1993).

3) Kawatake S., Inagaki M., Miyamoto T., Isobe R., Higuchi R., Eur. J. Org. Chem., 1999, 765-769 (1999).

4) Yamada K., Matsubara R., Kaneko M., Miyamoto T., Higuchi R., Chem. Pharm. Bull., 49, 447—452 (2001).

5) Kaneko M., Kisa F., Yamada K., Miyamoto T., Higuchi R., Eur. J. Org. Chem., 2003, 1004-1008 (2003).

6) Yamada K., Hamada A., Kisa F., Miyamoto T., Higuchi R., Chem. Pharm. Bull., 51, 46-52 (2003).

7) Arao K., Inagaki M., Higuchi R., Chem. Pharm. Bull., 47, 687-689 (1999).

8) Arao K., Inagaki M., Higuchi R., Chem. Pharm. Bull., 49, 695-698 (2001).

9) Shin J., Seo Y., J. Nat. Prod., 58, 948—953 (1995).

10) Hattori T., Adachi K., Shizuri Y., J. Nat. Prod., 61, 823-826 (1998).

11) Higuchi R., Jhou J.-X., Inukai K., Komori T., Liebigs Ann. Chem., 1991, 745-752 (1991).

12) Vincenti M., Guglielmetti G., Cassani G., Tonini C., Anal. Chem., 59, 694-699 (1987).

13) Scribe P., Guezennec J., Dagaut J., Pepe C., Saliot A., Anal. Chem., 60, 928-931 (1988).

14) Fusetani N., Yasumuro K., Matsunaga S., Hirota H., Tetrahedron Lett., 30, 6891-6894 (1989).

15) Jung J.-H., Lee C.-O., Kim Y.-C., Kang S.-S., J. Nat. Prod., 59, 319 322 (1996).

16) Subrahmanyam C., Kulatheeswaran R., Rao C.-V., Indian J. Chem., 35B, 578-580 (1996).

17) Hue N., Montagnac A., Païs M., Serani L., Leprévote O., Menou J.-L., Debitus C., Eur. J. Mass Spectrom., 7, 409-417 (2001).

18) Higuchi R., Kagoshima M., Komori T., Liebigs Ann. Chem., 1990, 659-663 (1990).

19) Higuchi R., Harano Y., Mitsuyuki M., Isobe R., Yamada K., Miyamoto T., Komori T., Liebigs Ann., 1996, 593-599 (1996).

20) Kawatake S., Nakamura K., Inagaki M., Higuchi R., Chem. Pharm. Bull., 50, 1091-1096 (2002).

21) Higuchi R., Inagaki M., Togawa K., Miyamoto T., Komori T., Liebigs Ann. Chem., 1994, 79-81 (1994).

22) Higuchi R., Inagaki M., Togawa K., Miyamoto T., Komori T., Liebigs Ann. Chem., 1994, 653-658 (1994).

23) Yamada K., Hara E., Miyamoto T., Higuchi R., Isobe R., Honda S., Eur. J. Org. Chem., 1998, 371-378 (1998).

24) Yamada K., Sasaki K., Harada Y., Isobe R., Higuchi R., Chem. Pharm. Bull., 50, 1467-1470 (2002). 